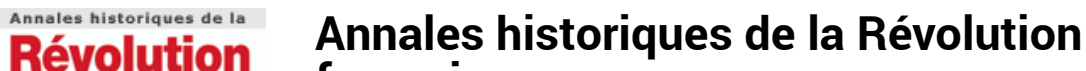

française française

343 | janvier-mars 2006

Varia

\section{Henri GRANGE, Benjamin Constant amoureux et républicain 1795-1799}

\section{Claudine Wolikow}

\section{(2) OpenEdition \\ Journals}

Édition électronique

URL : https://journals.openedition.org/ahrf/10312

DOI : 10.4000/ahrf.10312

ISSN : 1952-403X

Éditeur :

Armand Colin, Société des études robespierristes

Édition imprimée

Date de publication : 15 mars 2006

Pagination : 232-234

ISSN : 0003-4436

Référence électronique

Claudine Wolikow, « Henri grange, Benjamin Constant amoureux et républicain 1795-1799 ", Annales historiques de la Révolution française [En ligne], 343 I janvier-mars 2006, mis en ligne le 17 novembre 2008, consulté le 23 avril 2022. URL : http://journals.openedition.org/ahrf/10312 ; DOI : https:// doi.org/10.4000/ahrf.10312

Ce document a été généré automatiquement le 23 avril 2022

Tous droits réservés 


\title{
Henri GRANGE, Benjamin Constant amoureux et républicain 1795-1799
}

\author{
Claudine Wolikow
}

\section{RÉFÉRENCE}

Henri Grange, Benjamin Constant amoureux et républicain 1795-1799, Paris, Les Belles

Lettres, 2004, 382 p., ISBN 2-251-44272-3, $25 €$

1 Après un copieux ouvrage sur Les Idées de Necker (1974), et la publication longtemps attendue de l'inédit de Benjamin Constant, Fragments d'un ouvrage abandonné sur la possibilité d'une constitution républicaine dans un grand pays (1991), Henri Grange revient après d'autres, avec un titre accrocheur, sur l'entrée en politique du gentilhomme vaudois entre 1795 et 1799, des lendemains de Prairial à son entrée au Tribunat.

2 Avant 1795 ( 2 ch.), depuis la cour de Brunswick où il est pourvu d'un emploi honorifique, il s'enthousiasme dès 1789 pour la Révolution française, met en chantier en 1790 une réfutation de Burke, et soutient la république dès sa naissance. Il déserte alors la cour ducale où il passerait pour un dangereux démocrate. De retour en Suisse, il est accueilli à Coppet où il accomplit ses classes constitutionnelles sous la houlette de Necker père et fille.

En 1795 (1 ch.), accompagnée de Benjamin Constant, Mme de Staël rentre à Paris aux lendemains des «émeutes jacobines» (sic, p. 63) de Prairial. Convaincue par le Manifeste de Vérone et la descente à Quiberon de la nocivité irréaliste et vengeresse des projets royalistes, Germaine se fixe pour mission de rallier les royalistes constitutionnels à la république sans démocratie en gestation. Benjamin de son côté joue sa partition. Il effectue ses premiers pas politiques avec la publication (anonyme) d'un réquisitoire virulent contre le projet de décret des deux-tiers. Un mois plus tard, sollicité de son propre aveu par des avocats de la cause royaliste et gagné à l'amitié de Louvet, il fait volte-face, appelant au soutien sans faille de la nouvelle constitution et des conventionnels qui l'ont enfantée. Il aurait ainsi succombé à «l'intoxication» et à 
"l'amalgame " grossier confondant l'opposition gouvernementale avec le royalisme et la contre-révolution, schéma que l'auteur applique à Vendémiaire même, simple accès de colère légitime des bourgeois de Paris toujours interdits d'exercice du pouvoir par les «Perpétuels ».

De Vendémiaire à Fructidor (6 ch.), Benjamin s'émancipe de la tutelle et du salon de Germaine, entre en contact avec Barras, et s'engage résolument du côté de la politique directoriale. Il publie ses premières brochures : De la force du gouvernement actuel et de la nécessité de s'y rallier, Des réactions politiques et Des effets de la Terreur qui jalonnent, jusqu'aux élections de l'an $\mathrm{V}$, la controverse vigoureuse soutenue avec l'opposition " modérée ", Roederer et Lezay-Marnésia en tête, controverse naguère présentée par Ph. Raynaud (Champs-Flammarion, 1988), absent de la bibliographie. Durant cette phase activiste, où il est crédité de l'invention-création du Cercle constitutionnel, «sa chose» (p. 207), où il connaît l'apothéose dans la séance du 30 fructidor an $V$ célébrant la liberté sauvée, il aurait continué à pratiquer «l'amalgame» qui conforte l'exercice directorial-dictatorial du pouvoir par «l'aristocratrie du régicide» (Mme de Staël), et conduit à la collusion avec les généraux et à Fructidor, qui «n'est rien d'autre qu'une purge de style robespierriste ou stalinien» (p. 205). À l'appui de son indignation, l'auteur convoque deux témoins - et arbitres - phares, le sage Thibaudeau et l'intègre Roederer, assistés de Dupont de Nemours, Barante, et quelques autres, et entreprend à ce propos d'instruire le procès d'une présumée vulgate manichéenne et sommaire de l'historiographie directoriale toujours à l'honneur, invoquant en particulier A. Meynier contre G. Lefebvre et ses successeurs.

Prenant à la lettre, sans perspective tactique ou stratégique, les principes invoqués des professions de foi et la rhétorique politique du temps, H. Grange plaide, sous le choc des décrets des deux-tiers, l'émergence, martelée plusieurs dizaines de fois au fil des pages, d'un «parti constitutionnel» d'opposition authentiquement républicain, ou «parti modéré ", véritable adversaire et principale victime des Directoriaux, troisième force ignorée ou occultée par la vulgate, formée des "amis de l'ordre ", des " honnêtes gens", des "élites possédantes anti-gouvernementales ", foncièrement légalistes, dont Thibaudeau serait l'incarnation-type, et Roederer le porte-parole principal. Ce faisant, en dépit même des remarques empruntées à Mme de Staël, Henri Grange ne s'embarrasse guère des équivoques entretenues autour de la nébuleuse «constitutionnelle " et de sa sédimentation, ni du nuancier politique établi et enrichi depuis Aulard, G. Lefebvre et J.-R. Suratteau, jusqu'à l'actuel renouveau des études directoriales. Nulle page ne rappelle en quelle compagnie médiocrement républicaine se trouvait en Fructidor le conciliateur Thibaudeau - que G. Lefebvre au demeurant n'a jamais cessé d'identifier comme «républicain d'opposition» -. Adoptant la langue thermidorienne, ses convenances et son pouvoir d'intoxication, l'auteur n'hésite pas davantage à proprement bannir de la scène politique, étroitement circonscrite à la capitale, "l'engeance jacobine» (sic, p. 83), celle des « anarchistes, terroristes et buveurs de sang ou parti des sans-culottes » (p. 223), dont Antonelle était «l'un des chefs les plus dangereux »; il se montre ainsi plus exclusif que Benjamin Constant lui-même qui les admettait sur l'échiquier politique comme "l'artillerie du gouvernement». Symétriquement, toujours par refus de «l'amalgame », la « faction royaliste » est, jusqu'au printemps 1799, expédiée en coulisse en moins d'un paragraphe pour agitation superficielle et tapage inconsistant, et l'entrée en lice de Joseph de Maistre (Considérations sur la France) contre Benjamin passée sous silence. Ainsi H. Grange prend-il parti dans les combats du temps plutôt qu'il n'en explicite et historicise les termes et les enjeux, tournant le dos aux 
débats fondateurs laborieux et houleux sur l'admission du pluralisme politique et des droits de l'opposition, sur l'édification d'un exécutif républicain et l'élaboration conceptuelle de la démocratie représentative et de ses règles pratiques. Il mobilise au profit de l'hypothétique "parti constitutionnel » la distinction polémique opposée à Benjamin Constant par Lezay-Marnésia entre «majorité nationale » ou "réelle » et «majorité légale» ou "apparente» issue du scrutin comme évidence de la science politique, sans préciser que le même Lezay, dans le même texte (De la faiblesse d'un gouvernement qui commence, et de la nécessité où il est de se rallier à la majorité nationale), avait, comme d'autres en son temps, disqualifié le " parti central » ou " parti moyen » si cher à Thibaudeau comme " parti de sable » inopérant. Qui saurait dire positivement où penche «l'opinion nationale » en l'an V (en l'an VII) ? B. Constant peut-il être taxé d'amalgame lorsqu'il affirme que le peuple peut «se déclarer contre les gouvernants, sans être contre le Gouvernement » ou qu'« on a tort de prendre tous les mécontents pour des ennemis ». Les chefs royalistes étaient-ils moins pondérés dans l'avertissement donné au comte d'Artois en décembre 1797: "La France est toute royaliste ! Il eût été plus exact de dire : les Français, ou presque tous les Français, sont mécontents "; en janvier 1797, Joseph de Maistre ne s'avançait guère plus sur cette incertaine et indécise opinion publique : «On peut certainement disputer la majorité à la république, mais qu'elle l'ait ou qu'elle ne l'ait pas, c'est ce qui n'importe point du tout... ». L'appel lancé à réviser l'histoire du Directoire et des convulsions de Fructidor à la lumière de l'inflexible et lucide Thibaudeau, qui a pourtant convenu, dans ses Mémoires, de sa sous-estimation avérée, mais "partagée par beaucoup d'autres ", des forces royalistes, ne peut être pris raisonnablement au sérieux, tant il suppose un décor sur mesure et une lecture sélective et partiale des sources et des travaux (Meynier compris). La (dis)qualification de Benjamin Constant d'«éminence grise de Barras» (p.184), lequel dans ses Mémoires l'épingle comme «aide de camp de Talleyrand ", rapetisse singulièrement l'exploration libérale de l'établissement de la république.

6 Après Fructidor ( 3 ch.) vient pour Benjamin le temps des déconvenues, dramatisées en «Descente aux enfers ", triple effet du sursaut représentatif qui le ronge, du virage à gauche et du retour en force des «buveurs de sang » qui inspirent une acerbe campagne de la presse directoriale ou néo-jacobine contre «le professeur d'oligarchie » et «la déesse des oligarques bernois ", de la faillite enfin de ses ambitions électorales. Malgré de sérieux préparatifs, de la réactivation du Cercle constitutionnel du Palais-Royal à la scission provoquée à l'assemblée électorale de Versailles, en passant par ses offres de service - éventées - au cercle constitutionnel d'Evreux, Benjamin subit en l'an VI un échec cuisant, qui l'aurait empêché de jouer le rôle de chef d'un " parti constitutionnel » d'opposition dont H. Grange lui attribue l'ambition. Il ne parvient pas davantage, malgré la mobilisation staëlienne, à intégrer la députation du nouveau département du Léman. Dépité, il revient à Paris où, exclu de la compétition électorale de l'an VII, il s'empresse de signifier à Sieyès, dès son élection au Directoire, l'admiration qu'il lui voue, «l'espérance » qu'il lui redonne, et son soutien prononcé au révisionnisme républicain.

7 Après un emportement colérique contre la «dictature directoriale » et son masque usurpé de "République bourgeoise » colporté par la vulgate, l'admirateur de Necker revient in fine sur le moment d'égarement où Benjamin se serait fourvoyé - en compagnie de Germaine - jusqu'à prescrire une "cure de totalitarisme» (sic, p. 335) comme adjuvant à la phase initiale de croissance de la République: «erreur de 
jeunesse", accès de volontarisme impatient qui prétendaient forcer le cours de l'histoire, alors que la société française n'avait pas encore atteint la maturité républicaine requise.

8 Faute de conclure sur la continuité du conservatisme anti-jacobin farouche où s'est enferré et aveuglé le républicanisme constantien, l'auteur Épilogue (ch. final) sur les revirements ultérieurs et l'adhésion raisonnée du fructidorien repenti à une version monarchique du système représentatif, par un retour salutaire à la doctrine du « sage de Coppet ». Par une singulière pirouette, il soutient néanmoins que Constant n'aurait pour autant cessé d'être républicain, reportant simplement l'établissement de la république à l'échéance indéterminée de l'épuisement de la transition monarchique libérale. Ainsi s'agit-il moins d'apporter un contrefeu au girouettisme du Benjamin Constant muscadin d'Henri Guillemin (1958) que de profiler la figure du républicain désormais passif en faire-valoir du sage Necker. Ainsi va la trinité coppétienne... 